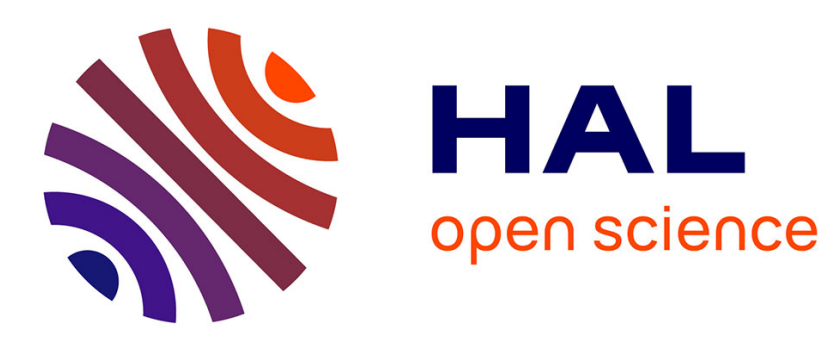

\title{
Plasma-Assisted Deposition at Atmospheric Pressure J. Salge
}

\section{To cite this version:}

J. Salge. Plasma-Assisted Deposition at Atmospheric Pressure. Journal de Physique IV Proceedings, 1995, 05 (C5), pp.C5-583-C5-592. 10.1051/jphyscol:1995569 . jpa-00253931

\section{HAL Id: jpa-00253931 https://hal.science/jpa-00253931}

Submitted on 1 Jan 1995

HAL is a multi-disciplinary open access archive for the deposit and dissemination of scientific research documents, whether they are published or not. The documents may come from teaching and research institutions in France or abroad, or from public or private research centers.
L'archive ouverte pluridisciplinaire HAL, est destinée au dépôt et à la diffusion de documents scientifiques de niveau recherche, publiés ou non, émanant des établissements d'enseignement et de recherche français ou étrangers, des laboratoires publics ou privés. 


\title{
Plasma-Assisted Deposition at Atmospheric Pressure
}

\author{
J. Salge
}

Institut für Hochspannungstechnik, Technische Universität Braunschweig, Westernwiese, 38229 Salzgitter, Germany

\begin{abstract}
In plasma-assisted deposition methods the activation energy necessary for the initiation of chemical reactions is transferred via charged particles. Due to this fact in many cases the process temperature can be kept small, if gas discharges at pressures below $1 \mathrm{hPa}$ are used. On the other hand low pressure requires a great deal of vacuum equipment. Processes at atmospheric pressure are more favourable, if similar results compared to existing methods can be achieved.

Basis for a new plasma-assisted deposition method at atmospheric pressure are barrier discharges. Those discharges consist of a large number of transient microdischarges in parallel which are distributed statistically on the surface to be coated.

Starting with some basic considerations on the repetitive generation of microdischarges, the deposition of thin polymeric films on glass surfaces is described, using barrier discharges at atmospheric pressure and acetylene. Uniform polymeric films up to $1 \mu \mathrm{m}$ are obtained, if trains of voltage pulses are used. Parameters influencing the deposition rate and the film quality are discussed. In addition, it is estimated whether further improvements of the deposition process are possible.
\end{abstract}

\section{INTRODUCTION}

It is an advantage of plasma-assisted deposition methods, that energy necessary for the initiation of chemical reactions of molecules or atoms is transfered via charged particles. A characteristic example is the plasmapolymerisation process, which uses low pressure glow discharges. A monomeric gas is excited in such a way, that a polymeric film is casted down on a surface [1]. Ions accelerated in the cathode fall and electrons in the plasma have a dominant influence on the film formation. Electrons can be accelerated up to energies of $10 \mathrm{eV}$ enough to crack bindings of monomeric gases which in the absence of gas discharges usually are obtained at much higher temperatures. The electrons absorb energy from the electric field which is transfered to the monomeric gas mainly by collisions; excited molecules, ions and radicals are formed [2]. The real polymerisation process is initiated on the surface itself [3]. Precondition for a uniform film deposition is that the glow discharges cover the surface homogeneously.

The use of low pressure in conventional plasma deposition processes means a restriction. It requires a great deal of vacuum equipment. Mainly in order to simplify process conditions and to save equipment, different authors have investigated whether similar results compared to existing processes can be obtained 
with discharges at atmospheric pressure. For instance in [4] is described a plasma polymerisation reactor which operates at atmospheric pressure. The circuit and the reactor are shown in fig. 1.

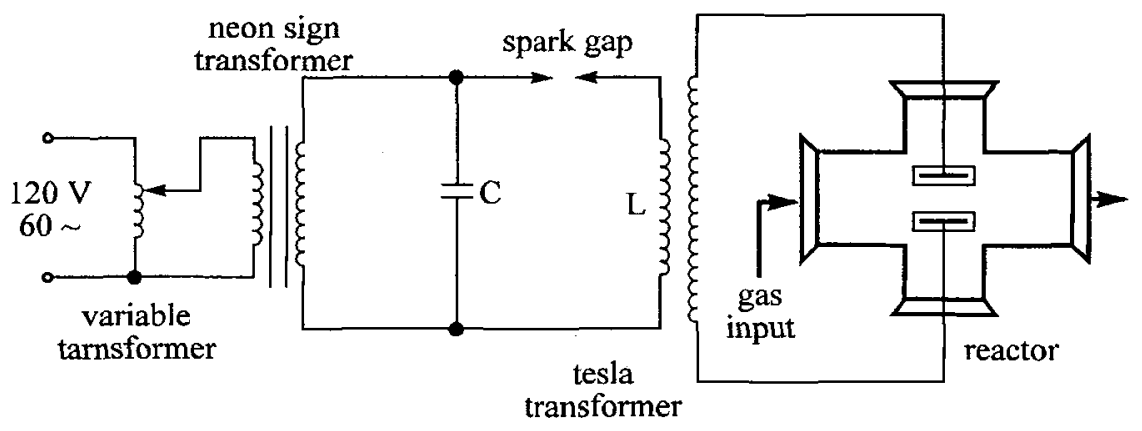

fig. 1: schematic of reactor and discharge circuit [4]

The reactor consists of a glass pipe cross. Both electrodes had a $0,32 \mathrm{~cm}$ thick polyester coating on each electrode face. The circuit consists of a $60 \mathrm{~Hz}$ power supply which charges the capacitor $\mathrm{C}$ in a $\mathrm{LC}$ resonant circuit to a voltage determined by the spark gap separation. When the spark gap fires, the circuit resonates and excites the secondary part of the Tesla transformer and a large ac voltage is applied across the electrodes in the reactor. With ethylene and helium as a diluent a uniform discharge could be maintained and films were deposited on glass microscope slides when oriented parallel to the electrode faces.

Another approach to generate an atmospheric pressure glow plasma suitable for film deposition on surfaces was undertaken by [5]. Their reactor is shown schematically in fig. 2 .

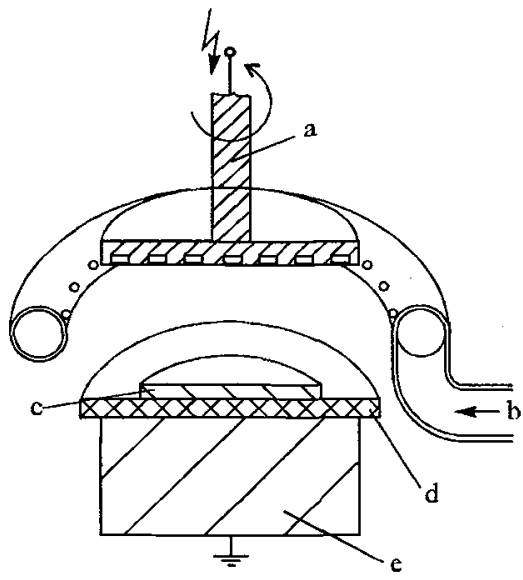

a rotating electrode

b gas flow

c substrate

d dielectric barrier

e earth electrode

fig. 2: film forming apparatus [5]

It consists of a rotating high voltage electrode and an earth electrode covered with a dielectric barrier. In order to obtain uniform thin films on surfaces it is necessary to generate a nearly uniform discharge which covers the surface homogeneously. This can be achieved by using helium as a diluent in addition to reactive gases and alternating current power sources, frequency $1 \mathrm{kHz}$. 
Reitz e. a. $[6,7,8]$ and Schwarz $[9,10]$ have demonstrated meanwhile, that uniform films also can be deposited on surfaces by transient discharges at atmospheric pressure, which are not uniform and which consist of a large number of statistically distributed microdischarges. Diluent gases are not necessary. In the following the actual knowledge of this method together with some ideas for a further development are outlined.

\section{BARRIER DISCHARGES AT ATMOSPHERIC PRESSURE}

Basis for the deposition method investigated by Reitz [6] and Schwarz [10] are so called barrier discharges. They can be generated in gaps between two electrodes, where at least one electrode is covered by a dielectric material (fig. 3 ).

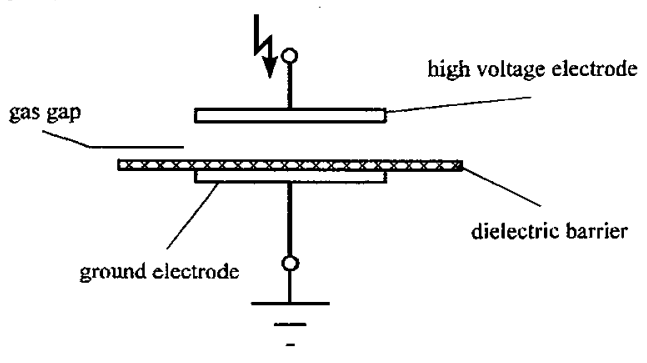

fig. 3: electrodes with dielectric barrier

If an alternating voltage is applied to the electrodes, breakdown processes are initiated in the gas gap and transient microdischarges are established. In principle, discharges of this type are well known from the treatment of polymer surfaces [11] and from the production of ozone [12], but in order to bring to mind the processes important for film deposition on surfaces it is useful to consider the development of one microdischarge in detail first. In fig. 4 four phases are shown schematically [10].

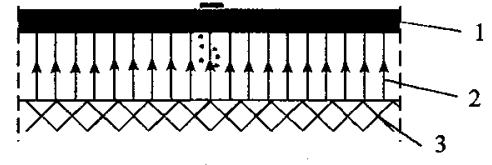

1 high voltage electrode

2 electric field lines

3 earth electrode

(1) Townsend-phase

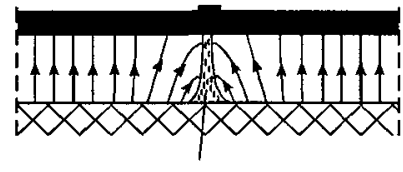

discharge channel

(2) ionisation or streamer phase

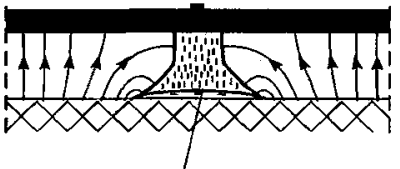

electron concentration

(3) phase of cathode sheath forming

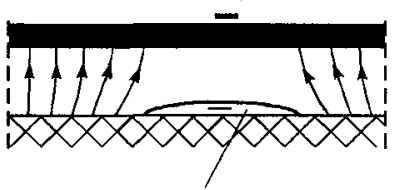

surface charge

(4) die out phase

fig. 4: development of microdischarges 
The discharge starts with a "Townsend-Phase" [13]. The number of electrons grow exponentially without disturbing the electric field determined by the form of the electrodes. The second phase is the "ionisation or streamer phase". A conducting channel bridges the gas gap. The next phase is characterized by the formation of a "cathode sheath". The current achieves its maximum and the current density is comparable with the density obtained in low pressure glow discharges. In the course of the discharge development electrons are accumulated at the surface of the dielectric barrier, which reduce the electric field in the gas gap drastically and the microdischarge dies out (phase 4, fig. 4). Across the surface the electric field strength is increased by the presence of these charges and surface discharges can occur. After the microdischarge is extinguished charges remain at the surface. The complete discharge development has a duration of some nanoseconds. The current is predominantly carried by electrons. The ion temperature remains close to room temperature.

Microdischarges of this type, which can be generated in different gases at atmospheric pressure, have some properties similar to those of low pressure glow discharges. Different is that the processes important for film formation on surfaces are concentrated locally at the footprints of the discharges and that the discharges are transient; their duration is limited to some nanoseconds.

For a uniform film deposition it is necessary that the surface is covered completely with footprints of microdischarges. In order to learn more about the discharge development in time and space, experiments have been conducted which allowed to observe the discharge footprints on the surface of a glass barrier via a transparent electrode [10]. The footprints could be exposured by a CCD camera. The test chamber is shown in fig. 5.

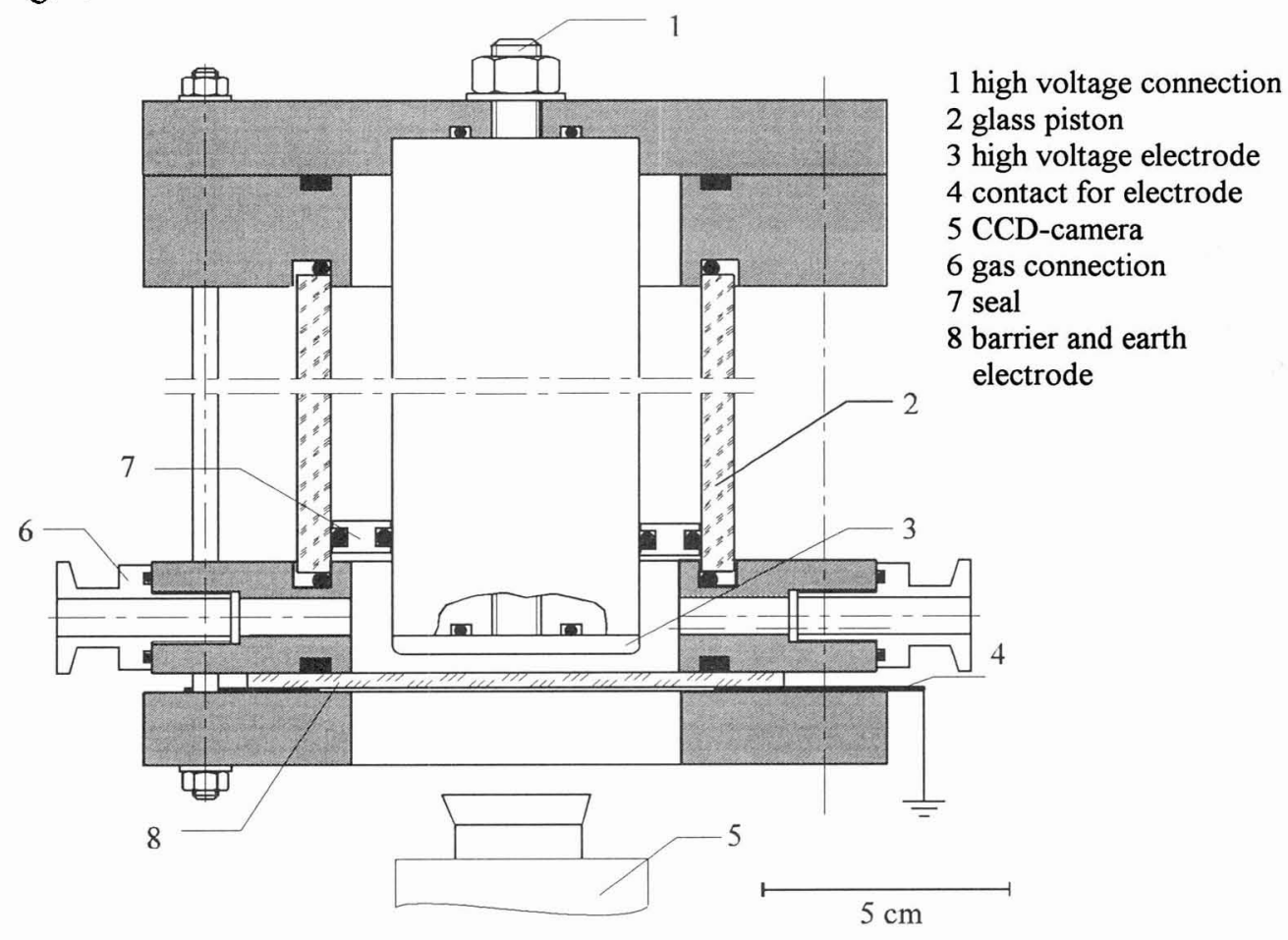

fig. 5: test chamber with transparent earth electrode 

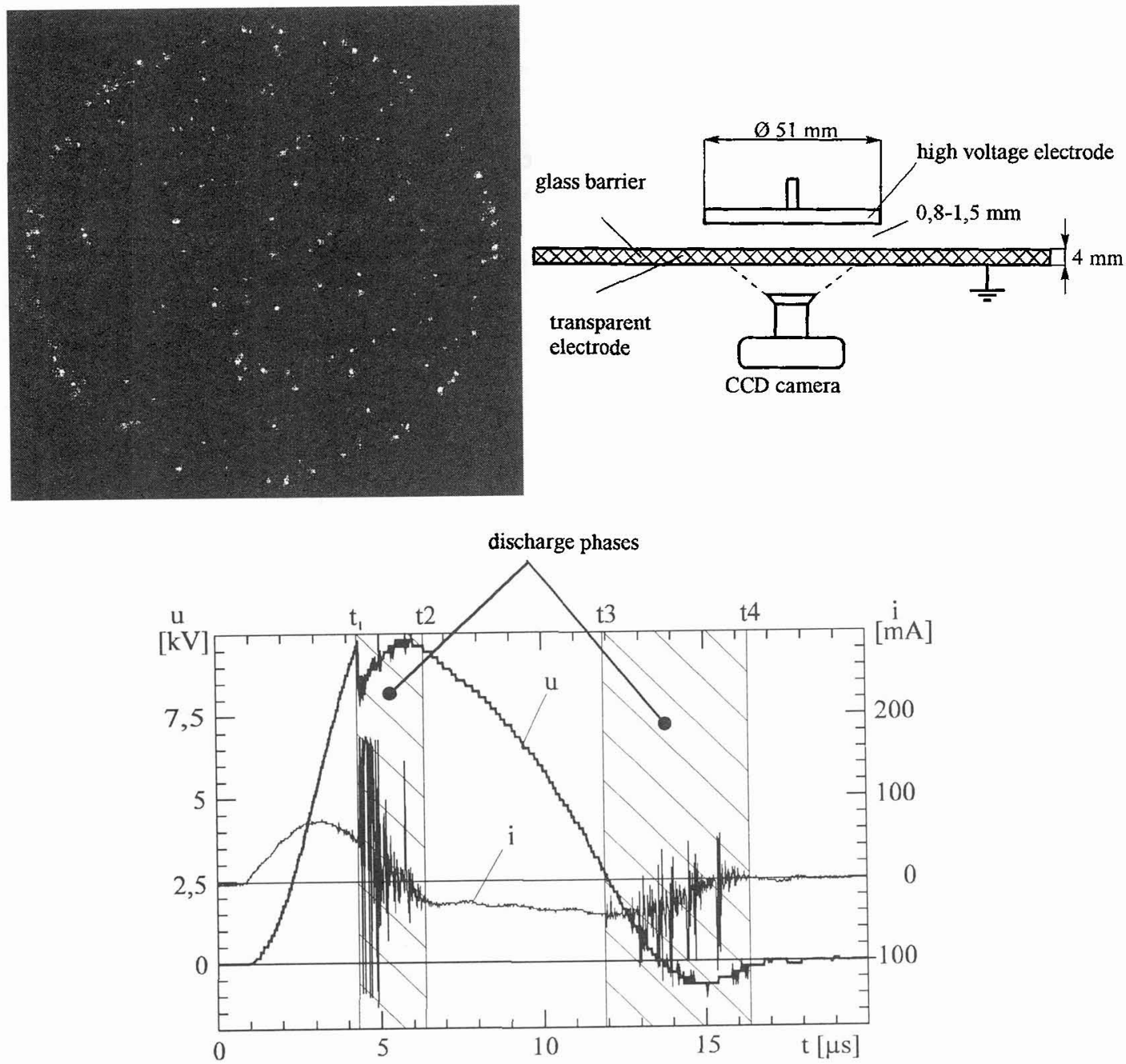

fig. 6: footprints of microdischarges together with voltage and current wave forms

Fig. 6 shows a photo of the footprints of microdischarges obtained in acetylene at atmospheric pressure via a transparent electrode and a glass barrier, when a single voltage pulse is applied. In addition, the voltage pulse and signals of the discharge current are given.

Two discharge periods, marked in fig.6, can be realized from the current signal. The first period starts when the voltage across the gas gap is positive and a number of microdischarges in parallel is generated statistically distributed on the barrier surface. $2 \mu$ s later all microdischarges are extinguished and only a displacement current through the barrier continued. The second discharge period starts, when the voltage across the gap is still positive. This is mainly due to the charges remained at spots from the preceeding microdischarges on the surface of the glass barrier. These charges cause locally strong deformations of the electric field in the gas gap. If the voltage between the electrodes decreases these spots are preferential points for the initiation of a new microdischarge, now with opposite polarity. The microdischarges tend to use the same discharge channels. 
In order to cover the surface completely with microdischarges first of all discharge periods generated repetitively are necessary. But in addition, intervals without voltage stress across the gas gap are needed. During these intervals the electrical strength of the gas gap can be consolidated. This can be achieved by applying bursts of voltage pulses. Reitz [6] and Schwarz [10] have found that trains of discharge periods are a key to obtain a complete covering of surfaces by the footprints of microdischarges and a uniform film formation on surfaces if reactive gases are used. Different forms of voltage pulses -unidirectional and alternating polarity- are acceptable. Fig. 7 shows an example for a sinusoidal pulse train.

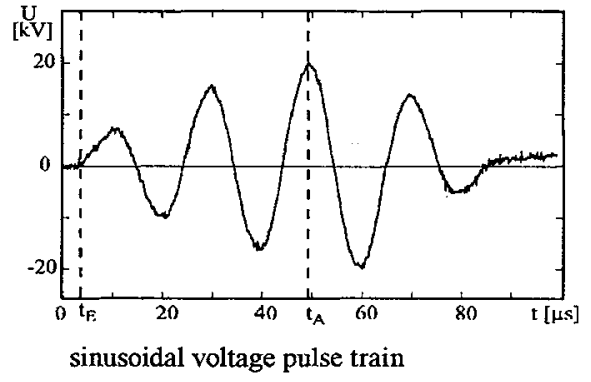

fig. 7: sinusoidal voltage pulse trains

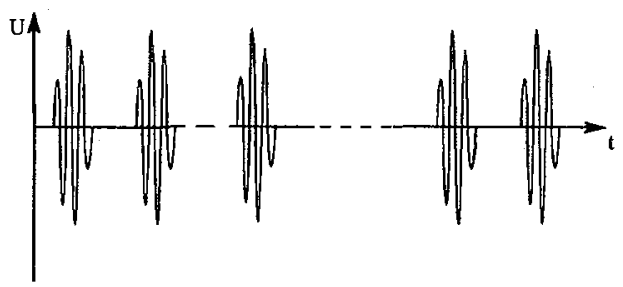

repetitive voltage pulse train

Power supplies suitable for the generation of voltage pulse trains of different waveforms have been investigated in Braunschweig [14]. Basis are generators well established in the field of corona treatment of surfaces. Generators of this type make use of the resonant circuit, which consists mainly of the capacitance of a barrier device and the leakage inductance of a transformer. By modification of the control system such power supplies can be enlarged that voltage pulse trains can be obtained. Meanwhile, such generators are commercially available [15]. A schematic diagram of such a power supply system is shown in fig. 8 .

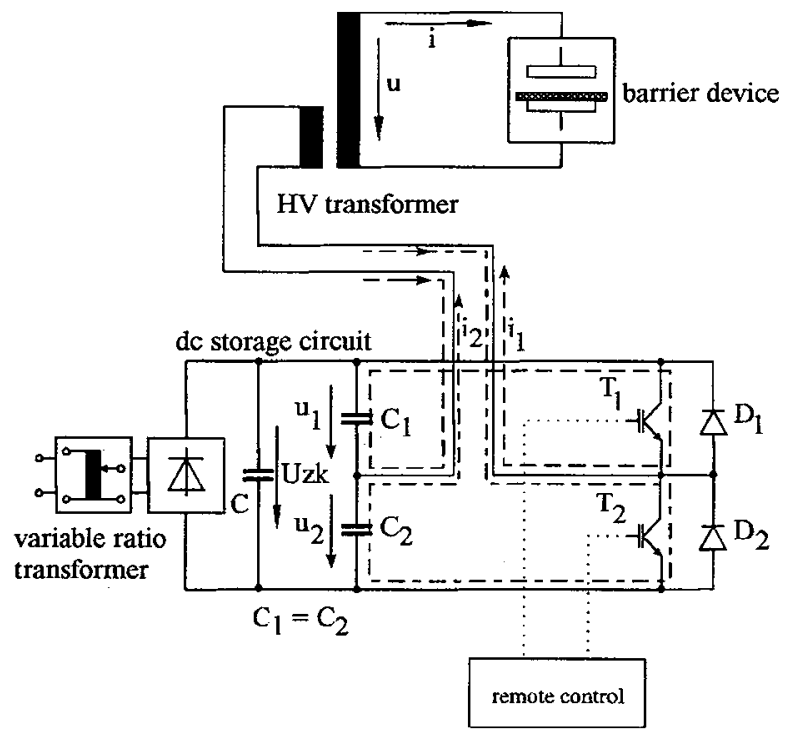

fig. 8: circuit diagram of a power supply system, suitable to generate voltage pulse trains at barrier devices 


\section{FILM DEPOSITION ON GLASS SURFACES}

The plasma-assisted film deposition method, developed by [6] and improved by [10] uses the statistic distribution of microdischarges on dielectric barriers, which can be controled by the amplitude and duration of voltage pulse trains and the intervals between discharge periods. They have demonstrated successfully the deposition of thin polymeric films at atmospheric pressure on glass plates. Their experimental results are the basis for further developments. The process vessel they used is shown in fig. 9.

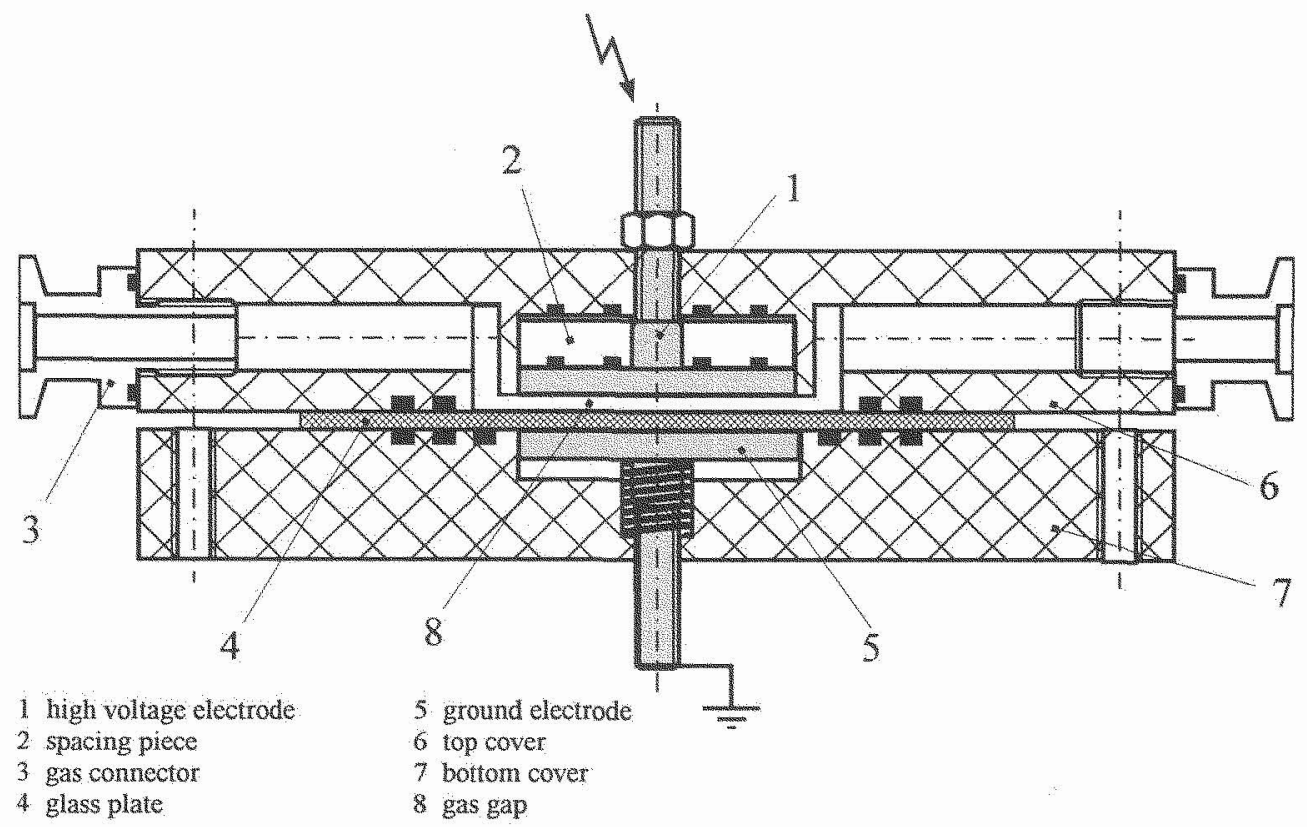

fig. 9: process vessel

The high voltage electrode (2) consists of aluminum, diameter $5,1 \mathrm{~cm}$. The glass plate (6) which covers the ground electrode (8) is the dielectric barrier. It has a thickness of $1 \mathrm{~mm}$. The gas gap (9) can have distances between 0,8 and $1,5 \mathrm{~mm}$. The gas is transmitted from the left gas connector (5) into the gap.

Reitz [6] and Schwarz [10] used the following procedure which is not yet optimized. First the surface has to be cleaned and activated. The gas gap is filled with argon (flow velocity $=51 \mathrm{tr} / \mathrm{min}$ ) and the surface is treated by microdischarges generated by voltage pulse trains for some minutes. After this cleaning procedure the gas gap is filled with a reactive gas, which was in most cases acetylene, sometimes ethylene. The gas flow rate is $0,5 \mathrm{ltr} / \mathrm{min}$. Now, the gap is stressed by bursts of voltage pulses. The voltage waveform can be of unidirectional or of alternating polarity. The length of a burst is around some ms followed by pauses of the order of a second. To produce a uniform film, of for instance $120 \mathrm{~nm}$ thickness, a total time of some minutes is needed. In relation to the integrated burst time -the intervals between the bursts are not considered- deposition rates up to $40 \mu \mathrm{m} / \mathrm{min}$ can be achieved with acetylene. If ethylene is used, the deposition rates are much smaller.

In this context it has to be mentioned, that there is an interdependance between film thickness and the duration of the pauses between the discharge periods: short pauses correspond to thin films (thickness of 
some $\mathrm{nm}$ ). For the generation of uniform films in the $\mu$ m-range larger pauses are necessary. The length of the bursts and the duration of the pauses influence the profile of the deposited films.

Using flat electrodes and acetylene the deposited films are uniform across the total area covered by the electrodes. Measured by mechanical scanning with a diamond probe, the films have a roughness $<5 \mathrm{~nm}$. Thicknesses up to $1 \mu \mathrm{m}$ have been achieved. Films cannot be removed by water or by an adhesive tape. In order to characterize the chemical structure of the film the infrared spectrum was measured with a spectrometer. A comparison with spectra of well known materials has indicated a resemblance to a spectrum of altered polyacetylene [16].

Up to now the deposition procedure has not been optimized finally and last but not least the process is not understood completely. Having in mind the similarities between transient microdischarges and low pressure glow discharges it is obvious that the film deposition process is similar to a plasmapolymerisation process obtained in low pressure glow discharges. During the development of microdischarges -mainly in the streamer phase- electrons and ions together with excited molecules and radicals are generated. Some of these particles are located close to the surface to be deposited, directly ready to initiate a polymerisation process. Radicals generated more far from the surface have to be transported to the surface until they can participate into the deposition process. The transport may be performed by microdischarges which appear later. Different to plasmapolymerisation at low pressure is that the polymerisation processes at atmospheric pressure are transient and localized to the footprints of microdischarges. Besides the properties of the reactive gas itself, the deposition process and the film formation are determined essentially by the microdischarge distribution on the surface. There exist an interdependance between spot charges, which remain on the dielectric material when touched by the microdischarge and the recovery behavior of the discharge channels in the gas gap. Generally rules valid do not exist.

\section{FURTHER DEVELOPMENT}

The results obtained by Reitz [6] and Schwarz [10] represent the first step in the development of plasmaassisted deposition at atmospheric pressure. The procedure is not restricted to glass plates and to acetylene. Meanwhile it could be demonstrated, that different kinds of plastic material and metal surfaces can be coated and different reactive gases and vapours can be used. It is the goal of running investigations in Braunschweig and Hamburg to find out whether this deposition method has the potential to be sufficient and economic compared to other existing deposition processes [14]. Important points considered are:

S Simplification and optimisation of the surface cleaning and activation process.

$\checkmark$ Development of an economic gas supply system.

Increasing the deposition rates.

Applicability of electrode systems with inhomogeneous electric field.

$\square$ Extrapolation to larger systems.

- Extension to moving foils to be activated and coated.

Concerning the last point fig. 10 shows an arrangement suitable for the deposition on moving plastic foils [14]. The foil to be treated is installed completely in a sealed box. The foil is coiled from one shaft to the other. Microdischarges can be generated between two electrodes the moving foil and an additional dielectric barrier. The gases are fed via nozzles through the gas gap. Without going more into details, results of first experiments have shown, that besides an increase of the surface tension by a discharge treatment in argon a further increase and a stabilisation of these conditions are obtained, if the foil surface 
after being activated in argon is treated with discharges in acetylene. This was obtained using different plastic foils [14].

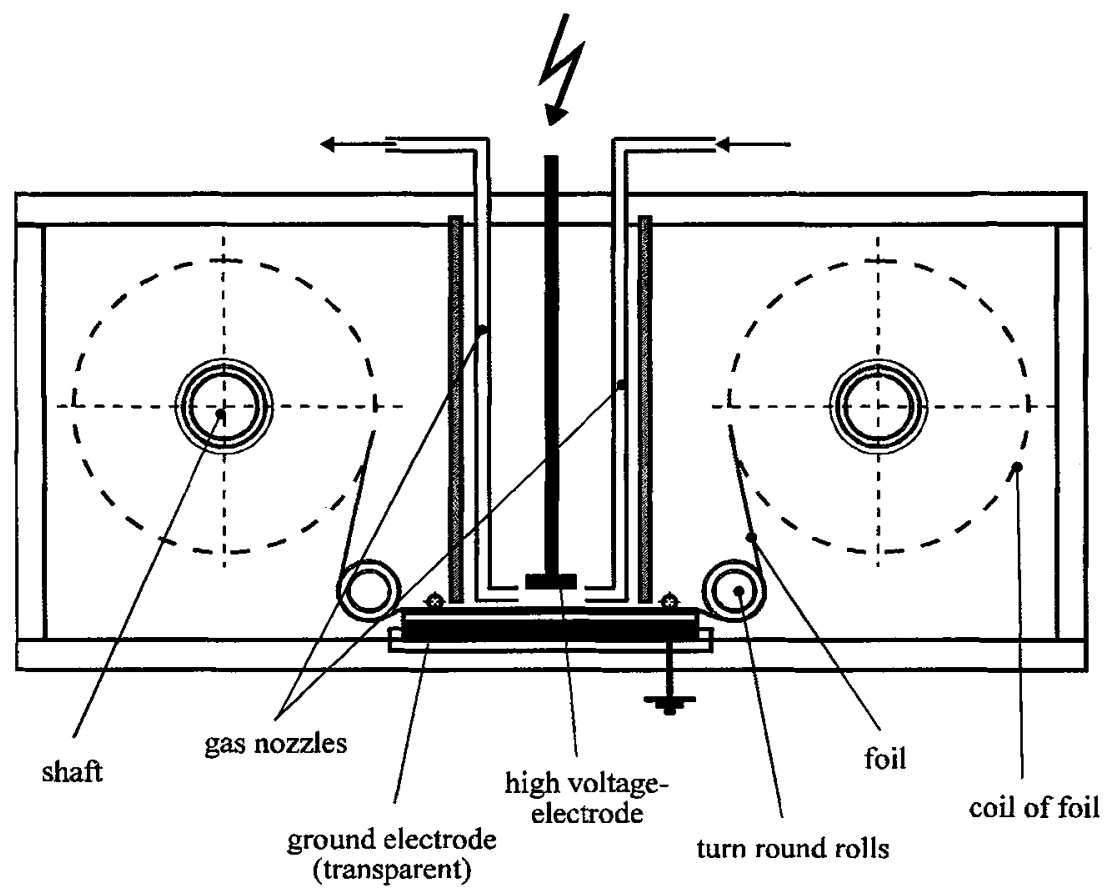

fig. 10: test chamber for foil treatment

\section{SUMMARY}

Barrier discharges at atmospheric pressure in combination with pure reactive gases have the capability to deposit thin films on surfaces. This is obtained with discharges, which consist of a large number of transient statistically distributed microdischarges of small dimensions and which are not in thermal equilibrium. The distribution of microdischarges on the surface can be controled by amplitude und duration of voltage pulse bursts and intervals between discharge periods. Different voltage waveforms can be accepted. If acetylene is used there exist similarities between processes going on in microdischarges at atmospheric pressure and plasmapolymerisation processes in conventional glow discharges at reduced pressure. Using flat electrodes and acetylene the deposited films are uniform across the total area covered by the electrodes. Thicknesses up to $1 \mu \mathrm{m}$ have been achieved. Besides glass plates plastic materials and metals have been coated. The method is also suitable for depositing thin films on moving foils and it can be extrapolated to larger systems. Although a number of encouraging results is obtained so far, there remain a lot of work to do to improve and to optimize this deposition method.

\section{Acknowledgement}

This work is conducted in close collaboration with Softal electronic $\mathrm{GmbH}$, Hamburg. It is supported by the German Ministery of Science and Technology (Reference No. 13N6313). The author is grateful to Dipl.-Ing. S. Meiners, TU Braunschweig, for useful discussions and for his help preparing this paper. 


\section{References}

[1] Frey H., Kienel G., „Dünnschichttechnologie“, VDI-Verlag, Düsseldorf (1987)

[2] Poll H.V., Tiller H.J., Wickleder K.M., „Polymere dünne Schichten“, Organische Festkörper und anorganische dünne Schichten, Akademische Verlagsgesellschaft Berlin (1978) pp.399-490

[3] Poll H.V., Zeitschrift für Angewandte Physik 29, (1970) p. 260

[4] Donohoe K.G., Wydeven T., Proceedings of the 4th Intern. Symposium on Plasma Chemistry, Zürich (1979) pp. 765-771

[5] Okazaki S., Kogoma M., Proc. Jpn. Symposium on Plasma Chemistry, Vol.2, (1988) pp. 95-102

[6] Reitz U., ,Barrierenentladung zur plasmagestützten Oberflächenbehandlung“, Thesis TU Braunschweig (1992)

[7] Reitz U., Salge J.G.H., Schwarz R., „Pulsed barrier discharge for thin film production at atmospheric pressure“, Surface and Coatings Technology, 59 (1993) pp. 144-147

[8] Reitz U., Salge J.G.H., Schwarz R., „Production of thin polymer films on glass surfaces using barrier discharges at atmospheric pressure", Proceedings of the 8th Intern. Symposium on high voltage engineering, Yokohama Japan 23-27 Aug. 1993

[9] Schwarz, R., Salge J.G.H., „Deposition of thin polymer films on surfaces using pulsed barrier discharges and pure reactive gases", Proceedings of 11 th Intern. Symposium on Plasma Chemistry, Loughborough Great Britain 22-27 Aug. 1993

[10] Schwarz, R., „Über die Beschichtung von Oberflächen mit Barrierenentladungen bei Atmosphärendruck“, Thesis TU Braunschweig (1995)

[11] von der Heide J. C., Wilson H. L., Guide to corona film treatment, Modern Plastics, 5 pp. 199-208 (1961)

[12] Eliasson B., Kogelschatz U., „Nonequilibrium volume plasma chemical processing“, IEEE Transactions on Plasma Science, Vol. 19, No. 6, (1991)

[13] Gibalov V., Pietsch, G., „Surface discharge phenomena in barrier discharges with dielectric anode“, Intern. Conference on Gas Discharges and their applications, Swansea, GB, (1992)

[14] Salge J., Schwarz R., Meiners S., „Oberflächenbeschichtung mit transienten Glimmentladungen bei Atmosphärendruck“, Proceedings of „Statusseminar“" on Oberflächen- und Schichttechnologien, 29-31 Mai 1995, Mainz, VDI-Verlag, Düsseldorf

[15] Prinz E., „Oberflächenbeschichtung mit transienten Glimmentladungen bei Atmosphärendruck“, Proceedings of „Statusseminar" on Oberflächen- und Schichttechnologien, 29-31 Mai 1995, Mainz, VDI-Verlag, Düsseldorf

[16] Gibson H. W., Pochan J. M., Chemical modification of polymers, oxidation of polyacetylene, Macromolecules, (1982)15 pp. 242-247 